\title{
Rice Stripe Mosaic Virus, a Novel Cytorhabdovirus Infecting Rice via Leafhopper Transmission
}

\author{
Xin Yang ${ }^{1}$, Jilei Huang'2, Chuanhe Liu², Biao Chen ${ }^{1}$, Tong Zhang ${ }^{1}$ and Guohui Zhou ${ }^{1 *}$ \\ ${ }^{1}$ Guangdong Province Key Laboratory of Microbial Signals and Disease Control, College of Agriculture, South China \\ Agricultural University, Guangdong, China, ${ }^{2}$ Instrumental Analysis and Research Center, South China Agricultural University, \\ Guangdong, China
}

\section{OPEN ACCESS}

Edited by:

Nobuhiro Suzuki,

Okayama University, Japan

Reviewed by:

Hideki Kondo,

Okayama University, Japan

Ralf Georg Dietzgen,

University of Queensland, Australia

${ }^{*}$ Correspondence:

Guohui Zhou

ghzhou@scau.edu.cn

Specialty section: This article was submitted to

Virology,

a section of the journal

Frontiers in Microbiology

Received: 04 September 2016 Accepted: 19 December 2016

Published: 04 January 2017

Citation:

Yang X, Huang J, Liu C, Chen B,

Zhang $T$ and Zhou G (2017) Rice

Stripe Mosaic Virus, a Novel

Cytorhabdovirus Infecting Rice via

Leafhopper Transmission.

Front. Microbiol. 7:2140.

doi: 10.3389/fmicb.2016.02140
A new rice viral disease exhibiting distinct symptoms-yellow stripes, mosaic and twisted tips on leaves - was found in China. Electron microscopy of infected leaf cells revealed the presence of bacilliform virions and electron-translucent granular-fibrillar viroplasm in the cytoplasm. The enveloped viral particles were 300 to $375 \mathrm{~nm}$ long and 45 to $55 \mathrm{~nm}$ wide. The leafhopper Recilia dorsalis was able to transmit the virus to rice seedlings, which subsequently exhibited symptoms similar to those observed in fields. The complete genome of the virus was obtained by small-RNA deep sequencing and reverse transcription-PCR product sequencing. The anti-genome contains seven open reading frames (ORFs). The deduced amino acids of ORF1, ORF5, and ORF7 are, respectively, homologous to the nucleocapsid protein $(N)$, glycoprotein $(G)$, and large polymerase protein $(L)$ of known rhabdoviruses. The predicted product of ORF2 is identified as a phosphoprotein $(\mathrm{P})$ based on its multiple potential phosphorylation sites and 12.6 to $21.0 \%$ amino acid (aa) identities with the P proteins of plant rhabdoviruses. The product of ORF4 is presumed to be the viral matrix (M) protein for it shares 10.3 to $14.3 \%$ aa identities with those of other rhabdoviruses. The above five products were confirmed as the viral structural proteins by SDS-PAGE and aa sequencing analyses of purified virus preparation. ORF3 and ORF6 are considered to encode two nonstructural proteins with unknown functions. Phylogenetic analysis based on protein N, G, and L amino acid sequences indicated that the isolated virus, which we have tentatively named Rice stripe mosaic virus (RSMV), is a new species in the genus Cytorhabdovirus. To our knowledge, RSMV is the only cytorhabdovirus naturally infecting rice and the first reported leafhopper-transmitted cytorhabdovirus. Our surveys of rice fields indicate that RSMV occurs frequently in Guangdong Province, China. Although the disease incidence is low at present, it might become serious with the vector insect population increasing.

Keywords: Rice stripe mosaic virus, rice viral disease, cytorhabdovirus, leafhopper, Recilia dorsalis

\section{INTRODUCTION}

Rice (Oryza sativa) is one of world's major cereal food crops. In Asia, where more than $90 \%$ of rice production takes place (Bheemanahalli et al., 2016), rice viral diseases have recently had a serious effect on yield (Uehara-Ichiki et al., 2013). The International Committee on Taxonomy of Viruses ${ }^{1}$ (ICTV) currently recognizes 14 rice viruses, all arthropod-borne: one species each

\footnotetext{
${ }^{1}$ http://www.ictvonline.org/
} 
in genera Benyvirus, Bymovirus, Nucleorhabdovirus, Oryzavirus, Sobemovirus, Tungrovirus, and Waikavirus, two species in Fijivirus, two species in Phytoreovirus and three species in Tenuivirus. Five of them, Rice yellow stunt nucleorhabdovirus (RYSV, also named as Rice transitory yellow virus, RTYV, Nucleorhabdovirus), Rice stripe tenuivirus (RSV), Rice yellow mottle sobemovirus (RYMV), Rice stripe necrosis benyvirus (RSNV) and Rice necrosis mosaic bymovirus (RNMV) are distributed in mesophyll cells and induce yellowing or mosaic symptoms in infected leaves, while the remainders parasitize rice phloem cells and cause rice dwarfing and dark green leaves.

Rhabdoviruses, which have a negative-sense RNA genome of 11-16 kb, form a large family in the order Mononegavirales (Afonso et al., 2016; Dietzgen et al., 2016). This family is characterized by a broad host range including vertebrates, invertebrates, monocots and dicots, and some members are pathogens with significant impacts on public health, crop and livestock production (Jackson et al., 2005; Kuzmin et al., 2009; Dietzgen et al., 2016). In general, the genomes of rhabdoviruses encode at least five canonical proteins in the following conserved order: nucleocapsid protein $(\mathrm{N})$, phosphoprotein $(\mathrm{P})$, matrix protein $(\mathrm{M})$, glycoprotein $(\mathrm{G})$ and large polymerase protein (L) (3'-N-P-M-G-L-5') (Jackson et al., 2005; Ammar et al., 2009; Kormelink et al., 2011). Besides, two or more accessory genes are often located in the genome between N-P, P-M, and/or G-L genes (Walker et al., 2011).

As currently circumscribed, the family Rhabdoviridae comprises nine genera of animal-infecting viruses (Ephemerovirus, Lyssavirus, Novirhabdovirus, Perhabdovirus, Sigmavirus, Sprivivirus, Tibrovirus, Tupavirus, and Vesiculovirus) and four plant-infecting viruses (Cytorhabdovirus, Dichorhavirus, Nucleorhabdovirus, and Varicosavirus) (Afonso et al., 2016;
A

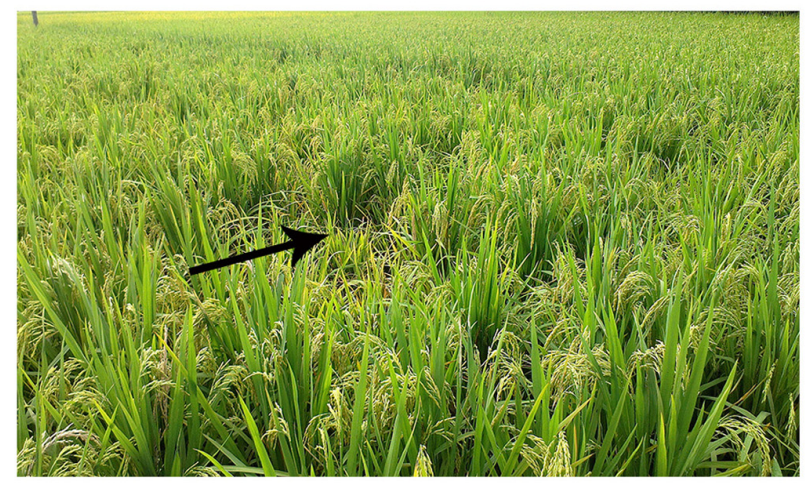

D

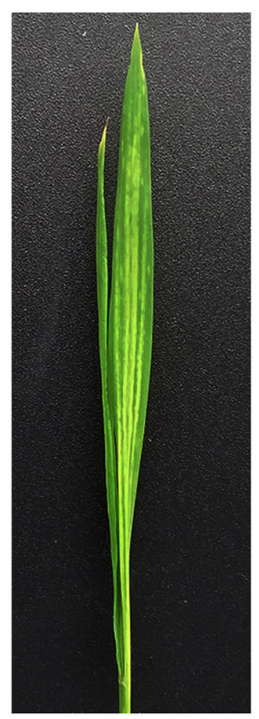

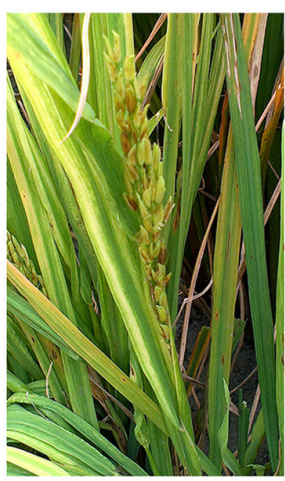

E

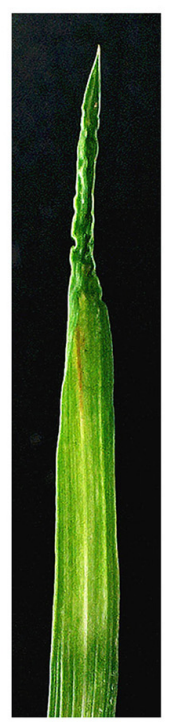

$\mathbf{F}$
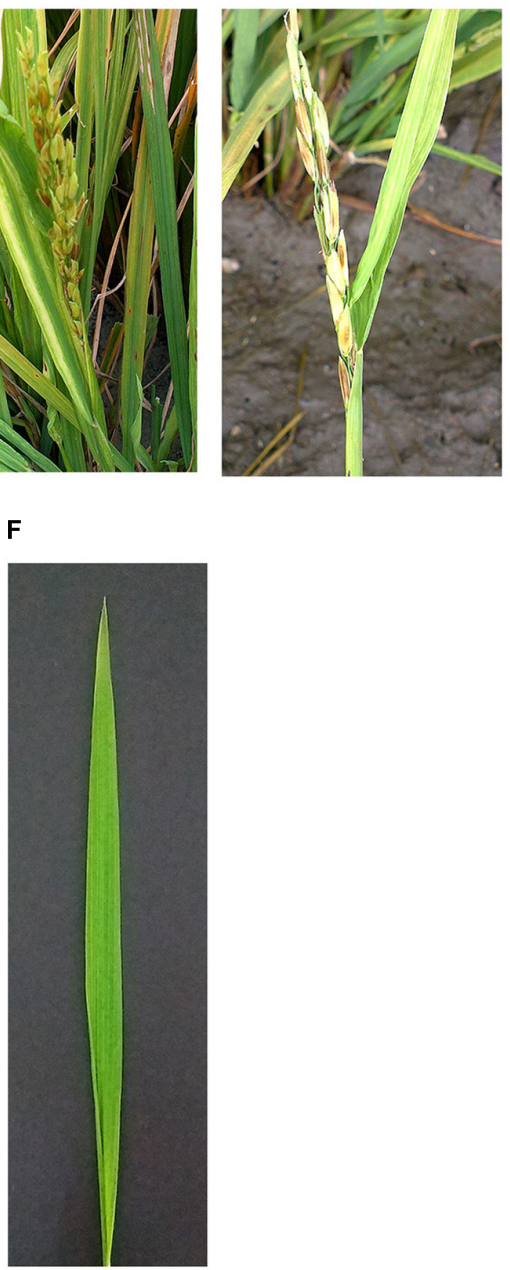

FIGURE 1 | Symptoms of Rice stripe mosaic virus (RSMV)-infected rice. Infected rice in the field (A-C). Infected rice leaves at 21 days after inoculation by the viruliferous vector Recilia dorsalis (D,E) and negative controls (F). The black arrow indicates RSMV-infected rice plant whose symptoms was shown in (B,C). The rice cultivar is Wuyou 736 in (A-C), and Taichung Native 1 in (D-F). 

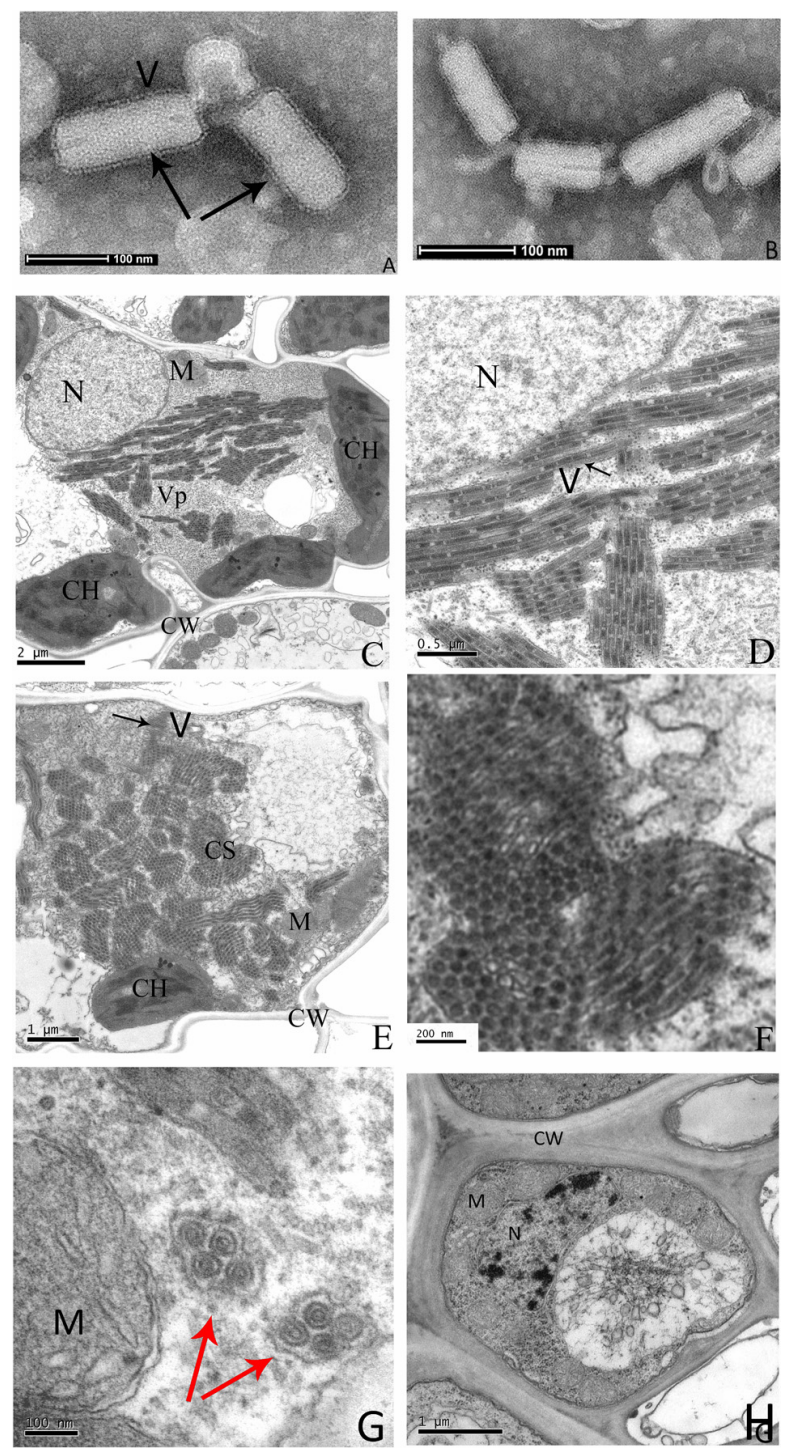

FIGURE 2 | Electron micrograph of infected rice leaves.

Negative-stained sap of infected rice leaves $\mathbf{( A , B ) . ~ U l t r a t h i n ~ s e c t i o n s ~ o f ~}$ infected rice leaves showing RSMV virions and cytopathological structures (C-G), the enlarged CS of (E) is shown in (F). The uninfected rice leaves cells are shown in (H). Black arrows indicate the RSMV virions with enveloped, red arrows indicate the vesicle structure with gathered virions in it. $\mathrm{CW}=$ cell wall, $\mathrm{CH}=$ chloroplast, $\mathrm{CS}=$ crystalline structure, $\mathrm{M}=$ mitochondrion, $\mathrm{N}=$ nucleus, $\mathrm{V}=$ Virion, and $\mathrm{Vp}=$ viroplasm.

Dietzgen et al., 2016). In addition, more than 75 plant rhabdoviruses have not been assigned to a genus. Arthropods, including aphids, leafhoppers and planthoppers, are common vectors for plant rhabdoviruses in nature (Jackson et al., 2005; Ammar et al., 2009).

The members of genus Nucleorhabdovirus are mainly transmitted by leafhoppers or planthoppers, and infect monocots and dicots in nature. Currently, RYSV is only species known naturally infecting rice (Huang et al., 2003). In the genus Cytorhabdovirus, the species are mainly transmitted by planthoppers or aphids, and infect monocots and dicots in nature. Neither rice infection nor leafhopper transmission has been observed in any members of this genus, except Wheat american striate mosaic cytorhabdovirus (WASMV) which can be transmitted by a leafhopper, Endria inimical (Jackson et al., 2005). Dichorhabdovirus and Varicosavirus are two new genera which recently approved by the ICTV (Dietzgen et al., 2014; Afonso et al., 2016). In the genus Dichorhabdovirus, which includes two species, orchid fleck virus (OFV) and coffee ringspot virus (CoRSV) infect monocots and dicots, respectively, through mite transmission, and in the genus Varicosavirus, which contains only one species, lettuce big-vein associated virus $(\mathrm{LBVaV})$ infects dicots by fungi transmission (Sasaya et al., 2002, 2004; Kondo et al., 2006; Ramalho et al., 2014).

In 2015, a new rice disease was observed in southern China. Affected rice plants exhibited slight dwarfing and the initial appearance of yellow stripes on leaves followed by mosaic and twisting of some leaves, and produced inferior heads bearing only a few, mostly unfilled grains. In this study, we detected a novel plant rhabdovirus in the infected plants by electron microscopy and small RNA sequencing. Artificial inoculation with the leafhopper Recilia dorsalis (Hemiptera: Cicadellidae) confirmed the novel virus as the disease pathogen. We next characterized the morphology and distribution of the virion in infected leaf cells, the viral structural proteins, its natural plant host range and insect vectors, features of the viral genome and phylogenetic relationships. We propose to name this virus as Rice stripe mosaic virus (RSMV), and classify it as a new member of the genus Cytorhabdovirus of the family Rhabdoviridae.

\section{MATERIALS AND METHODS}

\section{Sample Collection and Virus Transmission}

Plants with distinct symptoms were collected from a rice field in Taiping, Luoding, Guangdong Province, southern China, during October 2015 to May 2016. Representative weeds (Digitaria sanguinalis, Cynodon dactylon, Leptochloa chinensis, Eleusine indica, Paspalum distichum, and Monochoria vaginalis) as well as leafhoppers (Recilia dorsalis) were collected from or adjacent to the diseased fields. The leafhoppers was identified according to the document by Motschulsky (1859). Insect transmission of the virus was conducted with leafhopper $R$. dorsalis. Nonviruliferous leafhoppers collected from a non-diseased field were reared over two generations on four-leaf-stage seedlings of rice cultivar Taichung Native 1 . The seedlings were maintained in a plant growth chamber at $28^{\circ} \mathrm{C}$ and $80 \%$ relative humidity under a 16-h light/8-h dark photoperiod. The next generation nonviruliferous nymphs were then placed on diseased rice for a virus acquisition access period of 10 days. Rice seedlings at the three-leaf stage were inoculated with the viruliferous nymph leafhoppers for 3 days. The seedlings were then sprayed with insecticide ( $0.2 \%$ Isoprocarb) to kill all leafhoppers and were subjected to pathogen detection by electron microscope, 
A

RSMV

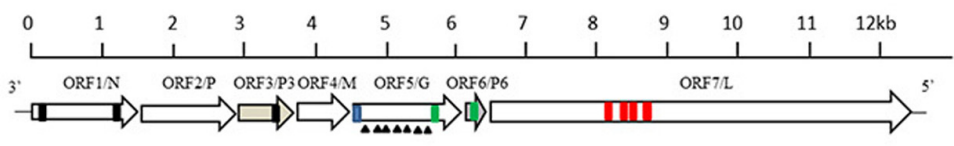

ISignal peptide ITransmembrane region $\Delta$ Predicted N-glycosylation site INotif (A-D) IPredicted nuciear locaization signal

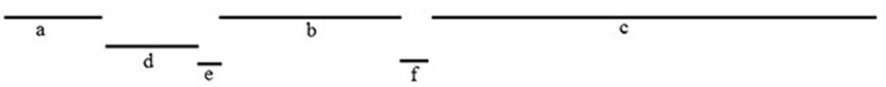

B

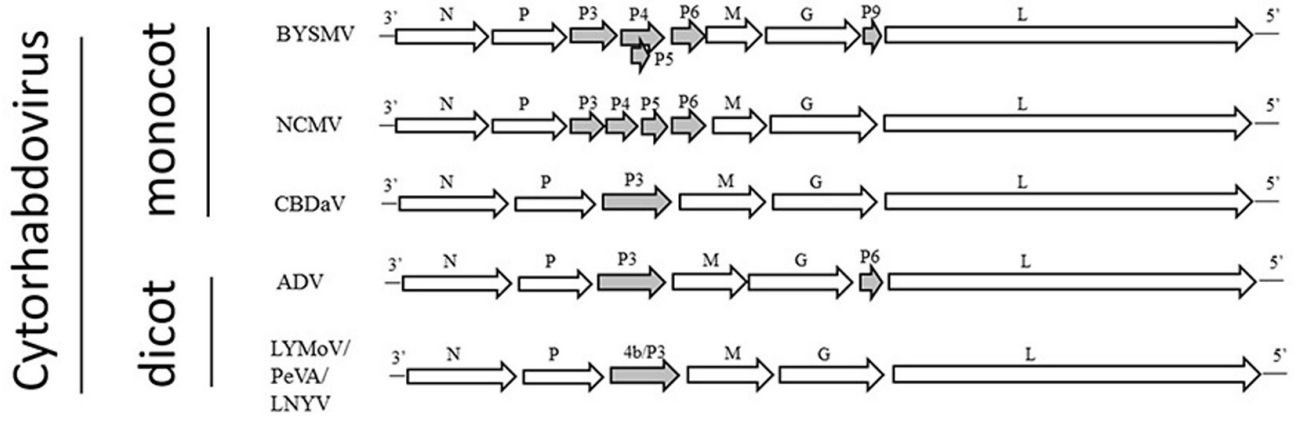

产
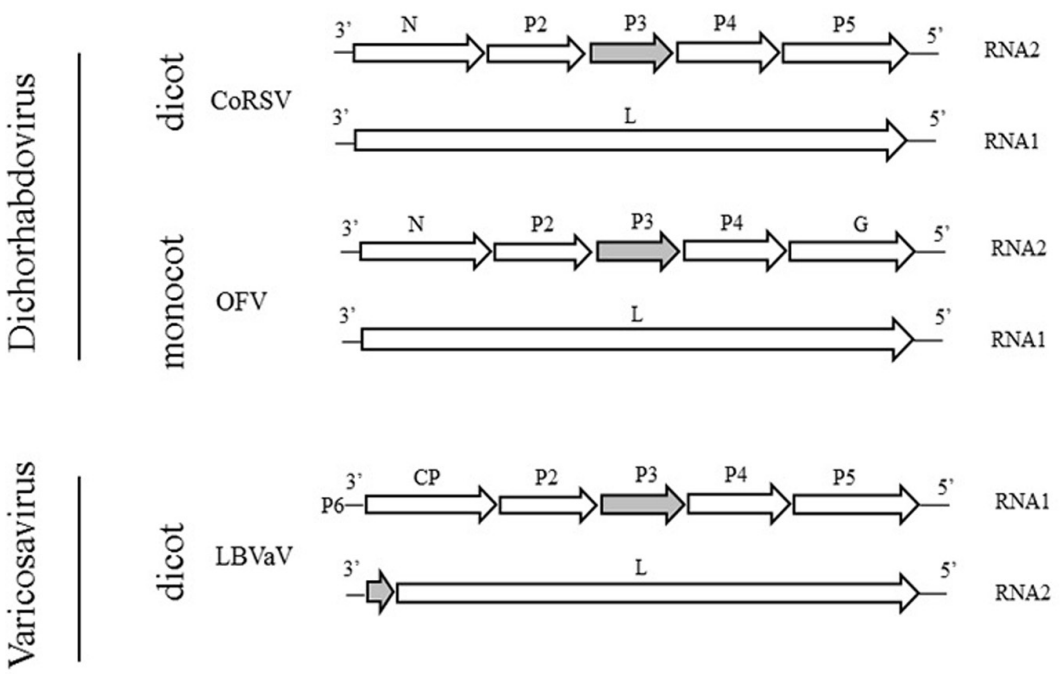

FIGURE 3 | Comparative genome organization of RSMV and plant-infecting rhabdoviruses. (A) Putative gene of RSMV are shown as black arrows on the anti-genomic strand. Fragments $a, b$, and c are contigs from small RNA sequencing that are similar to rhabdovirus N, G, and L genes, respectively. Contig fragments $\mathrm{d}$, e, and $\mathrm{f}$ showed no homology with any known viruses in NCBI and were mapped to the complete genome of RSMV. (B) Comparison of the genome structure of plant rhabdoviruses. Open reading frames (ORFs) for the main structural protein genes N, P, M, G, and L are indicated as open arrows. Ancillary genes are shown as gray arrows. 


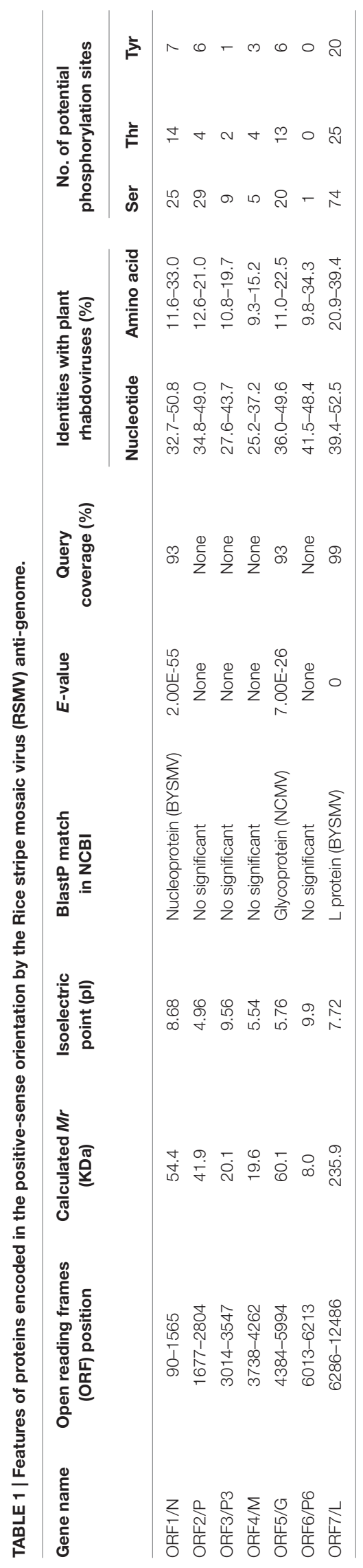

small RNA sequencing and reverse transcription-PCR (RT-PCR) another 10 days later. Mechanical transmission of the virus was attempted with reported previously method (Lamprecht et al., 2010).

\section{Electron Microscopy}

Crude sap from the viruliferous leafhopper inoculated rice leaves was negatively stained with $2 \%$ phosphotungstic acid ( $\mathrm{pH} 6.8$ ). Ultrathin sections were cut on an ultramicrotome and stained with uranium acetate and lead citrate (Li et al., 2015). Virion morphology and viroplasm distribution in the infected cells were examined under a transmission electron microscope (TECNAI G212, Holland).

\section{Virus Purification and Structural Protein Analyses}

Virus purification was conducted according to Heim et al. (2008). Briefly, two hundred grams of symptomatic rice leaves (grown in greenhouse after viruliferous leafhopper inoculation) were ground in extraction buffer ( $100 \mathrm{mM}$ Tris- $\mathrm{HCl}, \mathrm{pH} 8.0$ ), and filtered through cheesecloth and centrifuged at 5,000 rpm for $10 \mathrm{~min}$ at $4^{\circ} \mathrm{C}$. The supernatant was ultracentrifuged (45,000 rpm) for $30 \mathrm{~min}$ at $4^{\circ} \mathrm{C}$ and the pellets were resuspended in $3 \mathrm{~mL}$ of $100 \mathrm{mM}$ extraction buffer. The suspension was loaded on a discontinuous $20-40 \%$ sucrose density and centrifuged at $30,000 \mathrm{rpm}$ for $2 \mathrm{~h}$ at $4^{\circ} \mathrm{C}$. The light band was collected and ultracentrifuged $(45,000 \mathrm{rpm})$ for $40 \mathrm{~min}$ at $4^{\circ} \mathrm{C}$, the pellet was resuspended in $100 \mu \mathrm{L}$ resuspension buffer $(50 \mathrm{mM}$ Tris- $\mathrm{HCl}, \mathrm{pH}$ 8.0). All the ultracentrifuged procedures were done in a Beckman 100 Ti Rotor(XL-100K, Beckman, CA, USA).

After evaluated by electron microscope observation, the purified virus preparation was disrupted in loading buffer (50 mM Tris-HCl, pH 6.8, 2\% SDS, 1\% 2-mercaptoethanol, 10\% glycerol and $0.1 \%$ bromophenol blue), then the viral structural proteins were separated on 12\% SDS-PAGE (Kondo et al., 2009). The isolated protein bands were cut and digested with trypsin, peptides were sequenced by liquid chromatograph-mass spectrometry (LC-MS) (BGI, Shenzhen, China).

\section{Small RNA Library Preparation and Viral Genome Sequencing}

Total RNA was extracted from pools of five virus-infected rice leaves using an RNeasy Plant Mini Kit (Qiagen Germany). The RNA fragments between 140 and $150 \mathrm{nt}$ in size were isolated on a $12 \%$ polyacrylamide gels as describled by Wang et al. (2010), which was followed by sequencing on an Illumina Hiseq2500 sequencer performed by Sangon Biotech (Shanghai, China). The sequencing data were analyzed with SPAdes software (Sangon Biotech) to obtain contigs homologous to known viruses. To determine the nearly complete viral genome, specific primers were designed to close gaps between the three obtained contigs ( $\mathrm{a}, \mathrm{b}$ and $\mathrm{c}$ ), which were, respectively, similar to rhabdovirus N, G, and L genes (Figure 3A). To generate the terminal sequences of the viral genome, an RNA ligase-mediated rapid amplification of cDNA end (RLMRACE) (Liu and Gorovsky, 1993) was conducted using the 
TABLE 2 | Gene junction regions of RSMV and other rhabdoviruses.

\begin{tabular}{|c|c|c|c|c|}
\hline & RSMV & Gene end $\left(3^{\prime}\right)$ & Intergenic sequence & Gene start $\left(5^{\prime}\right)$ \\
\hline & $3^{\prime} \mathrm{le} / \mathrm{N}$ & AUUGUUUUCUUUUU & GCU & CUG \\
\hline & N/P & AUUCUUUUU & GCU & CUG \\
\hline & $\mathrm{P} / \mathrm{M}$ & AUUCUUUUU & GCU & CUG \\
\hline & M/P4 & AUUCUUUUU & GCU & CUG \\
\hline & $\mathrm{P} 4 / \mathrm{G}$ & AUUCUUUUU & GCU & CUG \\
\hline & G/P6 & AUUUUUU & GUCU & CUG \\
\hline & $\mathrm{P} 6 / \mathrm{L}$ & AUUCUUUUU & GCU & CUG \\
\hline & $\left\llcorner/ 5^{\prime} \operatorname{tr}\right.$ & CUUUUU & GCU & CUG \\
\hline & Consensus & AUUCUUUUU & GCU & CUG \\
\hline \multirow[t]{5}{*}{ Cytorhabdovirus } & ADV & CCAAAUUAUUU & GAU & CUU \\
\hline & LNYV & AUUCUUUU & $\mathrm{G}(\mathrm{N})_{\mathrm{n}}$ & CUU \\
\hline & NCMV & AUUCUUUUU & GACU & CUA \\
\hline & BYSMV & AUUAUUUUU & GA & CUC \\
\hline & LYMoV & AUUCUUUU & $\mathrm{G}(\mathrm{N})_{\mathrm{n}}$ & CUN \\
\hline \multirow[t]{9}{*}{ Nucleorhabdovirus } & DYW & AUUCUUUUU & GGU & UGU \\
\hline & PYDV & AUUAUUUUU & GGG & UUG \\
\hline & RYSV & AUUCUUUUU & GGG & UUG \\
\hline & SYNV & AUUCUUUUU & GG & UUG \\
\hline & MFSV & UUUAUUUU & GUAG & UUG \\
\hline & EMDV & AAUUAUUUUU & GGG & UUG \\
\hline & MIMV & AAUUCUUUUU & GGG & UUU/G \\
\hline & MMV & AAUUCUUUUU & GGG & UUG/A \\
\hline & TaVCV & AAUUCUUUUU & GGG & UUG \\
\hline \multirow[t]{2}{*}{ Dichorhabdovirus } & CoRSV & UAAAUUUAUUUU & GUA & GUU \\
\hline & OFV & UAAAUUUA/CUUUU & GU & UUG/N \\
\hline Varicosavirus & LBVaV & AUAAUCUUUUUU & $G$ & CUCU \\
\hline
\end{tabular}

viral RNA and viral cDNA after ligating their $3^{\prime}$ end with an adaptor (5'- PO4-ttccttatgcagctgatcactctgtgtcagttccagtcacgaca$\mathrm{NH} 2-3^{\prime}$ ) respectively. To avoid the potential mis-assembly, the obtained viral sequence was confirmed by re-sequenceing of the RT-PCR products from corresponding genomic regions. All primers used in this study are listed in Supplementary Table S1.

\section{Viral Genomic Sequence and Phylogenetic Analyses}

The complete nucleotide sequence of the discovered virus was analyzed with Lasergene DNAStar software. Predicted amino acids were compared using the NCBI BLASTp program $^{2}$, and potential phosphorylation and glycosylation sites were determined with NetPhos 2.0 (Blom et al., 1999) and NetNglyc1. $0^{3}$, respectively. The nuclear localization signals was predicted by cNLS Mapper (Kosugi et al., 2009). Sequence alignments of the nucleotide and predicted amino acids of the novel and other plant rhabdoviruses were carried out in CLUSTAL W. Phylogenetic trees were generated from the aligned sequences in MEGA 5.0 using the neighbor-joining method (Tamura et al., 2011).

${ }^{2}$ http://www.ncbi.nlm.nih.gov

${ }^{3}$ http://www.cbs.dtu.dk/services/NetNGlyc/

\section{Detection and Investigation of the Virus}

Total RNAs were isolated from rice leaf tissues or individual insects using an RNeasy Plant Mini Kit (Qiagen). RT-PCR amplification was carried out using a One-Step RNA PCR kit (Takara, Dalian, China) and the virus-specific detection primers listed in Supplementary Table S1. The following RT-PCR conditions were used: initial steps of $50^{\circ} \mathrm{C}$ for $30 \mathrm{~min}$ and $94^{\circ} \mathrm{C}$ for $2 \mathrm{~min}$, followed by 35 cycles of $94^{\circ} \mathrm{C}$ for $30 \mathrm{~s}, 55^{\circ} \mathrm{C}$ for $30 \mathrm{~s}$ and $72^{\circ} \mathrm{C}$ for $30 \mathrm{~s}$, and a final extension of $72^{\circ} \mathrm{C}$ for $10 \mathrm{~min}$. The amplified DNA fragments were excised from a 1.2\% agarose gel after electrophoresis and sequenced directly for analysis.

Field survey was carried out in Guangdong Province, China during 2015-2016. Suspicious rice samples were collected and analyzed by RT-PCR, with virus-positive products then directly sequenced.

\section{RESULTS}

\section{Disease Symptoms}

Our field investigation revealed that diseased plants exhibited slight dwarfing, with leaves showing yellow stripes, a mosaic appearance and occasional twisting. Diseased plants produced inferior heads that tended to remain only halfway emerged 


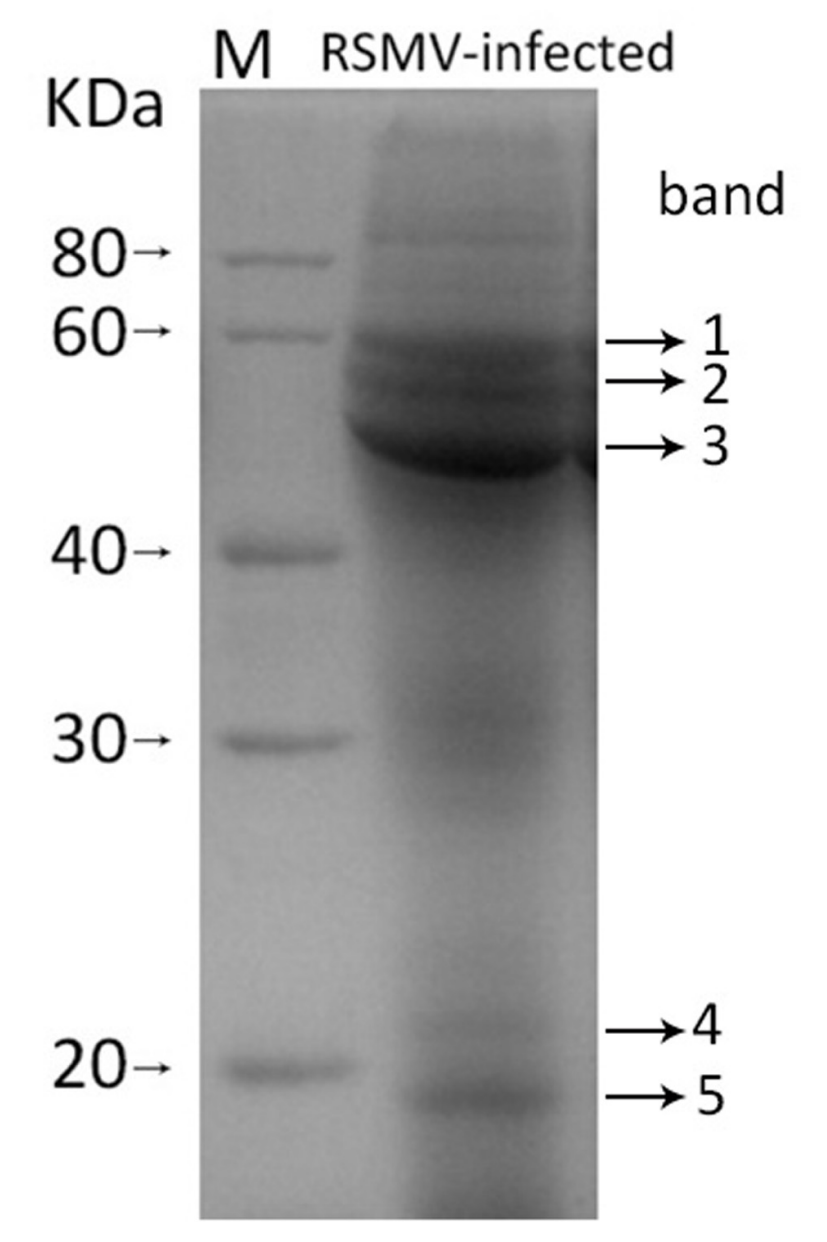

FIGURE 4 | SDS-PAGE pattern of purified SMRV preparation. The sample was resolved in $12 \%$ SDS-PAGE gel followed by staining with Coomassie brilliant blue-R250. Five protein bands (band 1 to 5) were analysis by LC-MS.

from leaf sheaths (Figures 1A,B). The grains were often unfilled (Figure 1C). Ten days after leafhopper $R$. dorsalis vector inoculation, new leaves of three-leaf-stage rice seedlings developed obvious yellow stripes, subsequently displayed mosaic symptoms and inward-curled tips (Figures 1D,E). While the control rice leaves with nonviruliferous leafhopper transmission showed no symptoms (Figure 1F).

\section{Virion Morphology and Cytopathology}

Negative staining of crude sap from diseased rice leaves revealed many enveloped bacilliform matured virions with $300-375 \mathrm{~nm}$ in long and $45-55 \mathrm{~nm}$ in wide $(n=50)$, and some broken viral particles with a minimum length $130 \mathrm{~nm}$ (Figures 2A,B). These virion sizes are similar to barley yellow striate mosaic virus (BYSMV) (Yan et al., 2015) and within the range of known members of plant rhabdoviruses (Jackson et al., 2005). These particles, which were absent from the nucleus, accumulated in cytoplasm and formed large numbers of crystalline structures that nearly occupied the entire cytoplasm space (Figures $\mathbf{2 C - F}$ ). Some virions were gathered and surrounded in vesicle (Figure 2G). Virions were found in infected leaf and vascular system cells, but were not present in cells of healthy plants (Figure $\mathbf{2 H}$ ).

\section{Characteristics of Complete Viral Genome and Virus Derived Amall RNA}

Approximately 10,119,447 individual small RNA raw reads were produced by deep sequencing. After removal of the adaptor sequence and low quality reads, 2,124,776 unique reads were obtained and all the small RNAs length was distribution between 17 and 35 nt. De novo assembly of the small RNAs by the Sangon Biotech Co., Ltd (Shanghai, China) with the SPAdes software obtained 1097 contigs. BlastN searches were performed to identify virus sequence with these contigs in the native database, 357 contigs were not matched to any viral genomes. The rest of contigs were searched again by BlastX in the National Center for Biotechnology Information (NCBI) data base. Three contigs (fragments $a, b$, and $c$ in Figure 3A) showed significant similarity to rhabdoviral $\mathrm{N}$ (40\% amino acid [aa] identity with BYSMV), G (23\% aa identity with northern cereal mosaic virus, NCMV) and L (39\% aa identity with BYSMV) proteins. To recover almost the entire genome, specific primers (Supplementary Table S1) based on the sequence of these three contigs were designed to close a few internal gaps. In addition, RT-PCR with an adaptor primer was performed to obtain viral genome terminal sequences. By comparing the three contigs against the whole genome as a reference, three other contigs were mapped to their genomic positions (fragments d, e, and $\mathrm{f}$ in Figure 3A). Finally, overlapping RTPCR was performed and amplicons were directly sequenced from both directions to verify the obtained RSMV genome sequence. The complete RSMV genome (GenBank accession no. KX525586) was found to comprise 12,782 nucleotides (nt), with $3^{\prime}$ leader and $5^{\prime}$ trailer sequences containing 89 and $296 \mathrm{nt}$, respectively.

In the developed small RNA library, the major size of unique small RNAs is $24 \mathrm{nt}$ reads (33.4\%), followed by $21 \mathrm{nt}(10.4 \%)$ (Supplementary Figure S1A), while for the RSMV-derived small RNAs, $21 \mathrm{nt}$ reads is majority (13.1\%) (Supplementary Figure $\mathrm{S} 1 \mathrm{~B})$, which is similar to other virus-derived small RNAs in Arabidopsis (Wang et al., 2010). In addition, the $5^{\prime}$ termini of RSMV-derived small RNAs are mostly Uridines (U), following with Adenines (A), Cytidines (C), and Guanines (G) in order (Supplementary Figure S1C). Furthermore, the mapped viral small RNAs to RSMV genome revealed that genome-derived small RNAs are more than antigenome-derived ones, and highest peaks are located in 3072 and 1701 nucleotide position of genome and anti-genome, respectively (Supplementary Figure S1D).

\section{RSMV Genome Analysis and Comparison With Other Plant Rhabdoviruses}

The complementary-sense RNA of RSMV was predicted to contain seven ORFs and has similar gene arrangement to most 
rhabdoviruses (Figure 3). The features of their encoded proteins are shown in Table 1. ORF1, containing 1,476 nt, putatively encodes a structural protein N. Sequence identities between the $\mathrm{N}$ protein of RSMV and those of plant rhabdoviruses (Cytorhabdovirus, Dichorhavirus, Nucleorhabdovirus and Varicosavirus) range from 32.7 to $50.8 \%$ (nt) and 11.6 to $33.0 \%$ (aa). The aa sequence of the RSMV N protein putatively contains two nuclear localization signals (NLSs) at amino (aa positions 14-45) and carboxy (aa positions 440-474) termini (Figure 3A). ORF2 is composed of 1,128 nt. Sequence identities between the encoded protein of RSMV and P proteins of plant rhabdoviruses range from 34.8 to $49.0 \%$ (nt) and 12.6 to $21.0 \%$ (aa). Although these aa identities are low, the ORF2-encoded protein is acidic (isoelectric point $[\mathrm{pI}]=4.96$ ) and possesses potential phosphorylation sites, similar to other rhabdoviruses (Jackson et al., 2005). These characteristics suggest that ORF2 encodes the viral structural protein P. ORF3, comprising 534 nt, has sequence identities with non-structural protein P3 of plant rhabdoviruses ranging from 27.6 to $43.7 \%$ (nt) and 10.8 to $19.7 \%$ (aa). It is a basic protein ( $\mathrm{pI}=9.56$ ), contains a NLS in the carboxy terminus (aa positions 143-173), and may be function as a movement protein. ORF4, containing $525 \mathrm{nt}$, was predicted to encode an matrix $(M)$ protein $(\mathrm{pI}=5.54)$. Sequence identities between the ORF4-encoded protein and plant rhabdoviruses range from 25.2 to $37.2 \%$ (nt) and 9.3 to $15.2 \%$ (aa). ORF5, which contains $1,611 \mathrm{nt}$, was predicted to encode a structural protein $G$ having a sequence identity with $\mathrm{G}$ proteins of plant rhabdoviruses ranging from 36.0 to $49.6 \%$ (nt) and 11.0 to $22.5 \%$ (aa). The amino terminal (aa positions 1-19) of this putative RSMV G protein possesses a signal peptide and seven potential glycosylation sites (aa positions 65, 232, 265, $366,381,403$, and 454). In addition, a transmembrane domain was predicted in the carboxy terminal (aa positions 481-503) (Figure 3A). ORF6 contains $201 \mathrm{nt}$ and putatively encodes a basic ancillary protein $(\mathrm{pI}=9.9)$ of unknown function, which we designated as P6. P6 contains a transmembrane domain (aa positions 26-43). Sequence identities between P6 and proteins of ADV, BYSMV and RYSV range from 41.5 to $48.4 \%$ (nt) and 9.8 to $34.3 \%$ (aa). The 6,201-nt ORF7 putatively encodes an L protein containing motifs characteristic of RNA-dependent RNA polymerases of negative-strand RNA viruses (Figure 3A) and including the GDNQ motif thought to represent the catalytic center (Dietzgen et al., 2006). Sequence identities between this $\mathrm{L}$ protein and those of other plant rhabdoviruses range from 39.4 to $52.5 \%$ (nt) and 20.9 to $39.4 \%$ (aa). Sequence identities (nt and aa) of these RSMV proteins compared with those of plant rhabdoviruses are listed in Supplementary Table S2.

Junctions between these protein-encoding genes identified in RSMV were analyzed with CLUSTA W. These sequences share three conserved regions: gene end, intergenic sequence and gene start (Table 2), which is a common characteristic of other rhabdoviruses (Yan et al., 2015; Dietzgen et al., 2006). The gene end $\left(3^{\prime}\right.$-AUUCUUUUU- $\left.5^{\prime}\right)$ is similar to those of other plant rhabdoviruses. The first nucleotide $(G)$ of the intergenic sequence is highly conserved in all reported plant rhabdoviruses. The gene start sequence of RSMV is predictively identical to that of known cytorhabdoviruses or varicosaviruses, which is $3^{\prime}-\mathrm{CU}-5^{\prime}$ (Table 2).

Our analysis revealed that RSMV $3^{\prime}$ leader and $5^{\prime}$ trailer sequences include a short complementary section that can putatively form a panhandle structure, a feature common to other rhabdoviruses (Supplementary Figure S2). In all known cytorhabdoviruses, these complementary sequences start with UGC/ACG (except for a G/C in the end of $3^{\prime}$ end of colocasia bobone disease-associated virus, $\mathrm{CBDaV})$; interestingly, in RSMV they begin with UUC/AAG-in other words, the second complementary nucleotide is U/A, not G/C.

\section{Confirmation of Viral Structural Proteins}

To confirm the viral structural proteins predicted by sequence identity, purified virus preparations were disrupted and the proteins were isolated by SDS-PAGE. Five protein bands with approximately molecular weight of $60,55,43,21$, and $19 \mathrm{KDa}$ were displayed (Figure 4). Based on their size, band 1, 2, 3 , and 5 probably correspond the predicted protein $\mathrm{G}, \mathrm{N}, \mathrm{P}$, and $\mathrm{M}$, respectively, while band 4 lacked counterpart. These bands were cut out and digested with trypsin, and then the peptides were sequenced by LC-MS. 57, 58, 96, 21, and 72 unique aa sequences were obtained from band 1, 2, 3, 4, and 5, respectively. Among them, three peptides from band 1 were successfully mapped on to the predicted RSMV protein

TABLE 3 | The identified peptides sequences of purified virus preparations by LC-MS analysis.

\begin{tabular}{|c|c|c|c|c|}
\hline Sample & $\begin{array}{l}\text { No. of identified } \\
\text { peptides }\end{array}$ & RSMV protein & $\begin{array}{l}\text { No. of peptides mapped on } \\
\text { to viral protein }\end{array}$ & Identified peptides sequences \\
\hline Band 1 & 57 & G protein & 3 & EIGNTFQVGHVIEPSSMIEVTDPLNVR; GSEEAEIVDSVNK; TAQIVLDR \\
\hline Band 2 & 58 & N protein & 27 & $\begin{array}{l}\text { AAYEAIGDEDSK; AEGVRDPMNIAGLDDISSR; AFLDDEEDDTAK; ASAGEYSSAMK; } \\
\text { ASDPDVSDVTEVK; SEYELTR; FGPFLAAYLMR; ATANTAWIAAQEAQK; } \\
\text { ATLDSATTDADTK; DALDAIMDILISFESTTK; DLGNSSPSTYAVER; DPMNIAGLDDISSR; } \\
\text { GSSNFFLTDYLPK; IASNVTESWEHMK; IILAEAPK; IVSTQFFQSLQTK; } \\
\text { KAAYEAIGDEDSK; LSLVPENTK; KGSSNFFLTDYLPK; LDQSTAEAGILR; } \\
\text { LLVLASHLYETK; LTSNYLIGAMR; LYSISPEAYSDDK; LYSISPEAYSDDKFDK; } \\
\text { NFYGYDAPSDLNCPEAGFLEQLK; SLFGDAGETVTDESK; YVAVLPLAYSGMHAMK }\end{array}$ \\
\hline Band 3 & 96 & P2 protein & 2 & AVISDSELNQAIR; IPGEIVSAVK \\
\hline Band 4 & 21 & None & 0 & - \\
\hline Band 5 & 72 & P4 protein & 6 & $\begin{array}{l}\text { DIYYLEVSNK; MSVTLIMEMNEDTPLK; TLYITGGGTSFR; } \\
\text { VINEETANQFIINDNAVR; VTGGSQLDYTSLIGSK; YPSYNAFESIFK }\end{array}$ \\
\hline
\end{tabular}




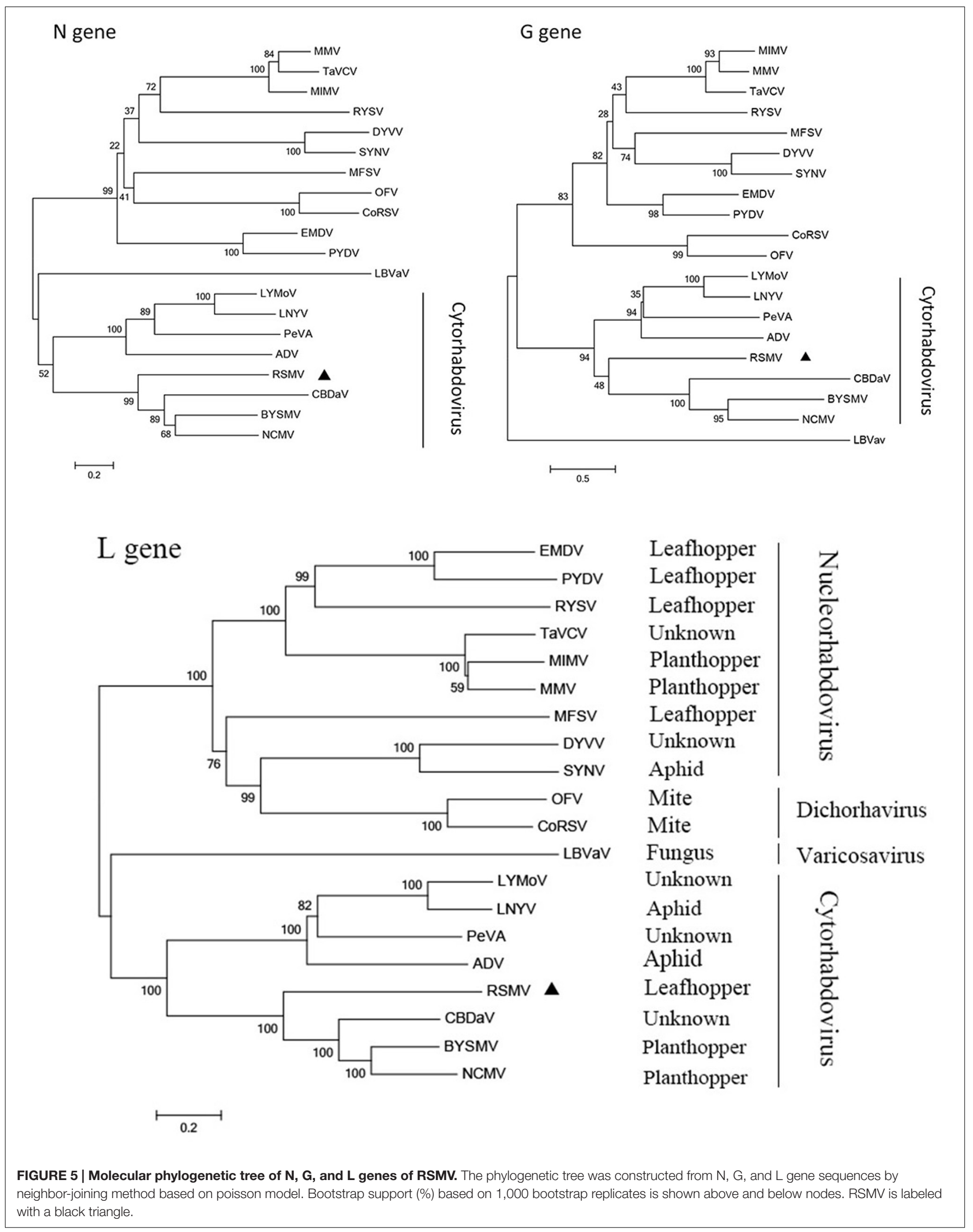


TABLE 4 | RSMV RT-PCR detection for rice samples collected from southern China in 2015 and 2016.

\begin{tabular}{|c|c|c|c|c|c|}
\hline Year & Sampling location (County) & Sampling field & Rice cultivar & No. of samples tested & No. of RSMV positive \\
\hline \multirow[t]{11}{*}{2015} & Taiping & 1 & Taifengyou 55 & 8 & 6 \\
\hline & & 2 & Hengfengyou 387 & 10 & 6 \\
\hline & & 3 & Wuyou736 & 11 & 8 \\
\hline & Songgui & 1 & Changyou736 & 8 & 7 \\
\hline & & 2 & Changyou736 & 11 & 7 \\
\hline & & 3 & Guyou1263 & 7 & 4 \\
\hline & Luoping & 1 & Hengfengyou 387 & 8 & 5 \\
\hline & & 2 & Yuemeizhan & 9 & 6 \\
\hline & Luoding & 1 & Yuyou 098 & 10 & 5 \\
\hline & & 2 & Guyou1263 & 8 & 4 \\
\hline & & 3 & Taifengyou 55 & 7 & 4 \\
\hline \multirow[t]{7}{*}{2016} & Songgui & 1 & Changyou736 & 10 & 10 \\
\hline & & 2 & Changyou736 & 10 & 8 \\
\hline & Lianzhou & 1 & Fengtianyou116 & 8 & 6 \\
\hline & & 2 & Fengtianyou116 & 7 & 6 \\
\hline & Taiping & 1 & Meiyou9822 & 20 & 20 \\
\hline & & 2 & Meiyou9822 & 28 & 25 \\
\hline & & 3 & Longyou766 & 10 & 9 \\
\hline Total & & & & 190 & 146 \\
\hline
\end{tabular}

G, 27 from band 2 on to the protein $\mathrm{N}$, two from band 3 on to the protein $\mathrm{P}$, and six from band 5 on to the $\mathrm{M}$, but none from band 4 on to any predicted viral protein (Table 3 ). Other peptide sequences were matched with rice, bacteria or unknown proteins. Therefore, we concluded that RSMV encoded G, N, P, M, and L (too large to isolate by SDS-PAGE) are the viral structural proteins which accord with the prediction by homology analyses.

\section{Phylogenetic Relationships between RSMV and Known Plant Rhabdoviruses}

To reveal the relationship of RSMV to other rhabdoviruses, we constructed phylogenetic trees of N, G and L protein (aa) sequences. According to the generated trees, RSMV appears to be a new member of cytorhabdovirus and is most closely related to $\mathrm{CBDaV}$ (Figure 5), and the genome organization is similarity except an additional gene between $\mathrm{G}$ and $\mathrm{L}$ gene (Figure 3). In the phylogenetic trees of $\mathrm{L}$ gene, the analyzed viruses are obviously divided into two groups: cytorhabdoviruses and nucleorhabdoviruses. The cytorhabdoviruses form two subgroups: one comprising viruses, including RSMV, that infect monocots, and the other representing pathogens of dicots. RSMV is transmitted by leafhoppers, where the other cytorhabdoviruses are transmitted by planthoppers, aphids or unknown vectors. GenBank accession numbers of rhabdovirus sequences used for comparisons and phylogenetic analyses are given in the Supplementary File S1.

In 2015-2016, RSMV-infected plants were found in many counties of southwestern Guangdong Province in southern China (Supplementary Figure S3). 190 suspicious samples collected from five counties were detected by RT-PCR and 146 were RSMV positive (Table 4). Disease incidences were generally 1 to $5 \%$; however, in some fields, the incidence was higher than $10 \%$, thereby seriously harming rice production (Figures $1 \mathrm{~A}-\mathrm{C}$ ). RT-PCR analysis revealed that the leafhoppers R. dorsalis could acquire the virus naturally, with a viruliferous rate of $56.8 \%$ (21 of 37) in the population collected from the field with about $10 \%$ diseased plants. This leafhopper could transmit RSMV to healthy rice seedlings with a high efficiency in the artificial transmission test. All plants (5/5) were infected with the virus after 3-day inoculation by five viruliferous leafhopper nymphs. The infection rate still reached $80 \%(8 / 10)$ and $50 \%(5 / 10)$ when two and one viruliferous insects placed to each plant, respectively. All artificial-infected plants showed symptoms similar to the naturalinfected ones (Figures 1D,E). RSMV could not be mechanically transmitted in our experiment, all 60 tested plants did not show any symptoms and were virus negative in RT-PCR detection. Other than rice, RSMV was only detected in asymptomatic crabgrass (Digitaria sanguinalis) collected from or adjacent to diseased rice fields, the virus was not detected in other sampled weeds.

\section{DISCUSSION}

Rhabdoviruses are widely present in nature and have a broad host range that includes vertebrates, invertebrates and plants (Jackson et al., 2005; Kuzmin et al., 2009). More than 100 plant rhabdoviruses have been reported, but most cannot be assigned to a genus because genome sequences and clearly identified replication sites are lacking (Jackson et al., 2005). In this study, small RNA sequencing and RT-PCR were performed to acquire the complete genome of an unidentified plant virus. Based on its morphological and pathological features, and phylogenetic relationships with other plant rhabdoviruses 
(Figure 5; Supplementary Table S2), we identified the virus as a new cytorhabdovirus in family Rhabdoviridae, and suggested it a tentative name RSMV. To our knowledge, RSMV is the first reported cytorhabdovirus naturally infecting rice and transmitted by a leafhopper.

Under an electron microscope, rhabdovirus particles often appear enveloped and either bullet-shaped or bacilliform (Jackson et al., 2005; Kormelink et al., 2011; Dietzgen et al., 2016). In our study, electron microscopy revealed the presence of enveloped, bacilliform virions rather than bullet-shaped particles in infected rice leaf cells (Figures 2A,B). Additionally, some viral particles was accumulated in intracellular vesicles (Figure 2G). This phenomenon is probably common for the plant rhabdoviruses due to budding occurs from the inner nuclear membrane or ER membrane and cytoplasmic vesicles (Jackson et al., 2005), and was also observed in animal infecting rhabdoviruses, vesicular stomatitis indiana virus (VSIV, genus Vesiculovirus) (Hackett et al., 1968) and niakha virus (NIAV, genus unassigned) (Vasilakis et al., 2013) suggesting the alternative intracellular transport for virus budding in animal, but its function in plant is unclear. Furthermore, lettuce necrotic yellows virus (LNYV) particles had been observed in the perinuclear spaces with blistering on the outer nuclear membrane, and LNYV multiplication appears to occur in the nucleus at early stages (Wolanski and Chambers, 1971). In our study, examination of ultrathin sections found that some viral particles were near the nucleus and adhered to the nuclear membrane (Figures 2C-E), suggesting that viral RNA synthesis and/or maturation of RSMV is probably similar to LNYV at early stages of infection.

Analysis of the RSMV genome revealed that RSMV carries seven non-overlapping genes in the order $3^{\prime}-\mathrm{N}-\mathrm{P}-\mathrm{P} 3-\mathrm{M}-\mathrm{G}-\mathrm{P} 6-\mathrm{L}-$ $5^{\prime}$ (Figure 3A). It is generally known that rhabdoviruses encoded five major structural proteins (N, P, M, G, and L protein). In this study, we confirmed that RSMV encoded N, P, M, G, and $\mathrm{L}$ are viral structural proteins by purified protein sequencing. We did not find other viral proteins in the purified virus preparation probably because of the sensitivity limit of the staining method in SDS-PAGE analyses. There have been researches indicating that the RYSV and sonchus yellow net virus (SNYV) viral MP and $\mathrm{P} 6$ protein can also be detected in their matured virions (Scholthof et al., 1994; Huang et al., 2003; Hiraguri et al., 2012). The P3 encoded by RSMV shared only $10.8 \%$ to $19.7 \%$ identities with the counterparts of other plant rhabdoviruses (Table 2), whether it function as a movement protein like in other virus (Walker et al., 2011; Mann and Dietzgen, 2014) need further experiment evidence. A transmembrane region is found in RSMV P6, similar to BYSMV P9 (Yan et al., 2015) and alfalfa dwarf virus (ADV) P6 (Bejerman et al., 2015), indicating it can probably be located on or transported through membrane. Its function requires further investigation, though its counterpart in RYSV has been identified as a systemic RNA silencing suppressor (Guo et al., 2013), however in LNYV the P protein serves as RNA silencing suppressor in plants (Mann et al., 2015; Bejerman et al., 2016). In addition, the seven genes are separated by conserved intergenic regions containing putative regulatory signals that have been reported in other rhabdoviruses (Jackson et al., 2005;
Walker et al., 2015; Dietzgen et al., 2016). As a typical feature of all rhabdoviruses, the $3^{\prime}$ and $5^{\prime}$ end sequences of RSMV are complementary (Supplementary Figure S2) and can form a putative panhandle structure thought to be involved in genome replication (Jackson et al., 2005).

Some cytorhabdoviruses may induce host nucleus changes in the early stages of infection (Jackson et al., 2005). In the case of RSMV, the $\mathrm{N}$ proteins contain two predicted NLSs (Figure 3A), which have been identified in nucleorhabdoviruses but not cytorhabdoviruses (Jackson et al., 2005). Moreover, the ADV $\mathrm{N}$ and $\mathrm{P}$ protein complex can locate to the nucleus though the absent of NLS in them (Bejerman et al., 2015). Determining whether RSMV $\mathrm{N}$ protein is locate to the nuclear membranes is worthy of future study. Finally, most of the phosphorylated residues in the RSMV P protein are serine residues (29/39; Table 1), similar to VSV (Mondal et al., 2014).

Most rice viruses are transmitted by arthropods, so their epidemiologic and distribution dependent on their vector (Hibino, 1996). Our field investigations indicate that RSMV is now mainly distributed in southwestern Guangdong Province of China (Supplementary Figure S3), where the virus vector leafhopper $R$. dorsalis is an increasing pest in rice field (Li et al., 2015). Although RSMV disease incidence is generally 1 to $5 \%$ at present, it might become seriously epidemic in this or even larger region with the leafhopper population increase because of warm weather. We thus believe that special attention should be focused on this new pathogen to minimize the potential for future outbreaks.

\section{AUTHOR CONTRIBUTIONS}

GZ: Conceived and designed the experiments. XY, BC: Performed the biological experiments. JH, CL: Observed the virion morphology. TZ: Analyzed the data. All authors read and approved the final manuscript.

\section{FUNDING}

This work was financially supported by the National Natural Science Foundation of China (31272012) and the Special Fund for Agro-scientific Research in the Public Interest (201303021).

\section{ACKNOWLEDGMENTS}

This work was financially supported by the National Natural Science Foundation of China (31272012) and the Special Fund for Agroscientific Research in the Public Interest (201303021). We thank Dr. Sek Man Wong for editing this manuscript.

\section{SUPPLEMENTARY MATERIAL}

The Supplementary Material for this article can be found online at: http://journal.frontiersin.org/article/10.3389/fmicb. 2016.02140/full\#supplementary-material 


\section{REFERENCES}

Afonso, C. L., Amarasinghe, G. K., Bányai, K., Bào, Y., Basler, C. F., Bavari, S., et al. (2016). Taxonomy of the order Mononegavirales: update 2016. Arch. Virol. 161, 2351-2360. doi: 10.1007/s00705-016-2880-1

Ammar, E., Tsai, C. W., Whitfield, A. E., Redinbaugh, M. G., and Hogenhout, S. A. (2009). Cellular and molecular aspects of rhabdovirus interactions with insect and plant hosts. Annu. Rev. Entomol. 54, 447-468. doi: 10.1146/annurev.ento .54 .110807 .090454

Bejerman, N., Giolitti, F., de Breuil, S., Trucco, V., Nome, C., Lenardon, S., et al. (2015). Complete genome sequence and integrated protein localization and interaction map for alfalfa dwarf virus, which combines properties of both cytoplasmic and nuclear plant rhabdoviruses. Virology 483, 275-283. doi: 10. 1016/j.virol.2015.05.001

Bejerman, N., Mann, K. S., and Dietzgen, R. G. (2016). Alfalfa dwarf Cytorhabdovirus $\mathrm{P}$ protein is a local and systemic RNA silencing supressor which inhibits programmed RISC activity and prevents transitive amplification of RNA silencing. Virus Res. 224, 19-28. doi: 10.1016/j.virusres.2016.08.008

Bheemanahalli, R., Sathishraj, R., Tack, J., Nalley, L. L., Muthurajan, R., and Jagadish, K. S. V. (2016). Temperature thresholds for spikelet sterility and associated warming impacts for sub-tropical rice. Agric. For. Meteorol. 221, 122-130. doi: 10.1016/j.agrformet.2016.02.003

Blom, N., Gammeltoft, S., and Brunak, S. (1999). Sequence and structure-based prediction of eukaryotic protein phosphorylation sites. J. Mol. Biol. 294, 13511362. doi: 10.1006/jmbi.1999.3310

Dietzgen, R. G., Callaghan, B., Wetzel, T., and Dale, J. L. (2006). Completion of the genome sequence of Lettuce necrotic yellows virus, type species of the genus Cytorhabdovirus. Virus Res. 118, 16-22. doi: 10.1016/j.virusres.2005.10.024

Dietzgen, R. G., Kondo, H., Goodin, M. M., Kurath, G., and Vasilakis, N. (2016). The family Rhabdoviridae: mono- and bipartite negative-sense RNA viruses with diverse genome organization and common evolutionary origins. Virus Res. 227, 158-170. doi: 10.1016/j.virusres.2016.10.010

Dietzgen, R. G., Kuhn, J. H., Clawson, A. N., Freitas-Astúa, J., Goodin, M. M., Kitajima, E. W., et al. (2014). Dichorhavirus: a proposed new genus for Brevipalpus mite-transmitted, nuclear, bacilliform, bipartite, negative-strand RNA plant viruses. Arch. Virol 159, 607-619. doi: 10.1007/s00705-013-1834-0

Guo, H., Song, X., Xie, C., Huo, Y., Zhang, F., Chen, X., et al. (2013). Rice yellow stunt rhabdovirus protein 6 suppresses systemic RNA silencing by blocking RDR6-mediated secondary siRNA synthesis. Mol. Plant Microbe Interact. 26, 927-936. doi: 10.1094/MPMI-02-13-0040-R

Hackett, A. J., Zee, Y. C., Schaffer, F. L., and Talens, L. (1968). Electron microscopic study of the morphogenesis of Vesicular stomatitis virus. J. Virol. 2, 1154-1162.

Heim, F., Lot, H., Delecolle, B., Bassler, A., Krczal, G., and Wetzel, T. (2008). Complete nucleotide sequence of a putative new Cytorhabdovirus infecting lettuce. Arch. Virol. 153, 81-92. doi: 10.1007/s00705-007-1071-5

Hibino, H. (1996). Biology and epidemiology of rice viruses. Annu. Rev. Phytopathol. 34, 249-274. doi: 10.1146/annurev.phyto.34.1.249

Hiraguri, A., Hibino, H., Hayashi, T., Netsu, O., Shimizu, T., Uehara-Ichiki, T., et al. (2012). The movement protein encoded by gene 3 of rice transitory yellowing virus is associated with virus particles. J. Gen. Virol. 93, 2290-2298. doi: 10.1099/vir.0.044420-0

Huang, Y., Zhao, H., Luo, Z., Chen, X., and Fang, R. X. (2003). Novel structure of the genome of Rice yellow stunt virus: identification of the gene 6-encoded virion protein. J. Gen. Virol. 84, 2259-2264. doi: 10.1099/vir.0.19195-0

Jackson, A. O., Dietzgen, R. G., Goodin, M. M., Bragg, J. N., and Deng, M. (2005). Biology of plant rhabdoviruses. Annu. Rev. Phytopathol. 43, 623-660. doi: 10.1146/annurev.phyto.43.011205.141136

Kondo, H., Maeda, T., Shirako, Y., and Tamada, T. (2006). Orchid fleck virus is a rhabdovirus with an unusual bipartite genome. J. Gen. Virol. 87, 2413-2421. doi: 10.1099/vir.0.81811-0

Kondo, H., Maeda, T., and Tamada, T. (2009). Identification and characterization of structural proteins of orchid fleck virus. Arch. Virol. 154, 37-45. doi: 10.1007/ s00705-008-0268-6

Kormelink, R., Garcia, M. L., Goodin, M., Sasaya, T., and Haenni, A. (2011). Negative-strand RNA viruses: the plant-infecting counterparts. Virus Res. 162, 184-202. doi: 10.1016/j.virusres.2011.09.028

Kosugi, S., Hasebe, M., Tomita, M., and Yanagawa, H. (2009). Systematic identification of cell cycle-dependent yeast nucleocytoplasmic shuttling proteins by prediction of composite motifs. Proc. Natl. Acad. Sci. U.S.A. 106, 10171-10176. doi: 10.1073/pnas.0900604106

Kuzmin, I. V., Novella, I. S., Dietzgen, R. G., Padhi, A., and Rupprecht, C. E. (2009). The rhabdoviruses: biodiversity, phylogenetics, and evolution. Infect. Genet. Evol. 9, 541-553. doi: 10.1016/j.meegid.2009.02.005

Lamprecht, R. L., Kasdorf, G. G. F., Stiller, M., Staples, S. M., Nel, L. H., and Pietersen, G. (2010). Soybean blotchy mosaic virus, a new Cytorhabdovirus found in South Africa. Plant Dis. 94, 1348-1354. doi: 10.1094/PDIS-09-09-0598

Li, S., Hao, W., Lu, G., Huang, J., Liu, C., and Zhou, G. (2015). Occurrence and identification of a new vector of Rice orange leaf phytoplasma in south China. Plant Dis. 99, 1483-1487. doi: 10.1094/PDIS-12-14-1243-RE

Liu, X., and Gorovsky, M. A. (1993). Mapping the $5^{\prime}$ and $3^{\prime}$ ends of Tetrahymena thermophila mRNAs using RNA ligase mediated amplification of cDNA ends (RLM-RACE). Nucleic Acids Res. 21, 4954-4960. doi: 10.1093/nar/21.21.4954

Mann, K. S., and Dietzgen, R. G. (2014). Plant rhabdoviruses: new insights and research needs in the interplay of negative-strand RNA viruses with plant and insect hosts. Arch. Virol. 159, 1889-1900. doi: 10.1007/s00705-014-2029-Z

Mann, K. S., Johnson, K. N., and Dietzgen, R. G. (2015). Cytorhabdovirus phosphoprotein shows RNA silencing suppressor activity in plants, but not in insect cells. Virology 476, 413-418. doi: 10.1016/j.virol.2014.12.023

Mondal, A., Victor, K. G., Pudupakam, R. S., Lyons, C. E., and Wertz, G. W. (2014). Newly identified phosphorylation site in the Vesicular stomatitis virus P protein Is Required for Viral RNA Synthesis. J. Virol 88, 1461-1472. doi: 10.1128/JVI.02384-13

Motschulsky, V. I. (1859). Homopteres. In "Insectes des Indes orientales, et de contrees analogues." Etud. Entomol. 8, 25-118

Ramalho, T. O., Figueira, A. R., Sotero, A. J., Wang, R., Geraldino Duarte, P. S., Farman, M., et al. (2014). Characterization of Coffee ringspot virus-Lavras: a model for an emerging threat to coffee production and quality. Virology 46, 385-396. doi: 10.1016/j.virol.2014.07.031

Sasaya, T., Ishikawa, K., and Koganezawa, H. (2002). The nucleotide sequence of RNA1 of Lettuce big-vein virus, genus Varicosavirus, reveals its relation to nonsegmented negative-strand RNA viruses. Virology 297, 289-297. doi: 10.1006/viro.2002.1420

Sasaya, T., Kusaba, S., Ishikawa, K., and Koganezawa, H. (2004). Nucleotide sequence of RNA2 of Lettuce big-vein virus and evidence for a possible transcription term ination/in itiation strategy similar to that of rhabdoviruses. J. Gen. Virol. 85, 2709-2717. doi: 10.1099/vir.0.80061-0

Scholthof, K. G., Hillman, B. I., Modrell, B., Heaton, L. A., and Jackson, A. O. (1994). Characterization and detection of sc4: a sixth gene encoded by Sonchus yellow net virus. Virology 204, 279-288. doi: 10.1006/viro.1994.1532

Tamura, K., Peterson, D., Peterson, N., Stecher, G., Nei, M., and Kumar, S. (2011). MEGA5: molecular evolutionary genetics analysis using maximum likelihood, evolutionary distance, and maximum parsimony methods. Mol. Biol. Evol. 28, 2731-2739. doi: 10.1093/molbev/msr121

Uehara-Ichiki, T., Shiba, T., Matsukura, K., Ueno, T., Hirae, M., and Sasaya, T. (2013). Detection and diagnosis of rice-infecting viruses. Front. Microbiol. 4:289. doi: 10.3389/fmicb.2013.00289

Vasilakis, N., Widen, S., Mayer, S. V., Seymour, R., Wood, T. G., Popov, V., et al. (2013). Niakha virus: a novel member of the family Rhabdoviridae isolated from phlebotomine sandflies in Senegal. Virology 444, 80-89. doi: 10.1016/j.vi rol.2013.05.035

Walker, P. J., Dietzgen, R. G., Joubert, D. A., and Blasdell, K. R. (2011). Rhabdovirus accessory genes. Virus Res. 162, 110-125. doi: 10.1016/j.virusres.2011.09.004

Walker, P. J., Firth, C., Widen, S. G., Blasdell, K. R., Guzman, H., Wood, T. G., et al. (2015). Evolution of genome size and complexity in the Rhabdoviridae. PLoS Pathog. 11:e1004664. doi: 10.1371/journal.ppat.1004664

Wang, X., Wu, Q., Ito, T., Cillo, F., Li, W., Chen, X., et al. (2010). RNAimediated viral immunity requires amplification of virus-derived siRNAs in Arabidopsis thaliana. Proc. Natl. Acad. Sci. U.S.A. 107, 484-489. doi: 10.1073/ pnas.0904086107

Wolanski, B. S., and Chambers, T. C. (1971). The multiplication of Lettuce necrotic yellows virus. Virology 44, 582-591. doi: 10.1016/0042-6822(71) 90372-2

Yan, T., Zhu, J., Di, D., Gao, Q., Zhang, Y., Zhang, A., et al. (2015). Characterization of the complete genome of Barley yellow striate mosaic virus reveals a nested gene encoding a small hydrophobic protein. Virology 478, 112-122. doi: 10. 1016/j.virol.2014.12.042 
Conflict of Interest Statement: The authors declare that the research was conducted in the absence of any commercial or financial relationships that could be construed as a potential conflict of interest.

The reviewer HK and handling Editor declared their shared affiliation, and the handling Editor states that the process nevertheless met the standards of a fair and objective review.
Copyright (c) 2017 Yang, Huang, Liu, Chen, Zhang and Zhou. This is an openaccess article distributed under the terms of the Creative Commons Attribution License (CC BY). The use, distribution or reproduction in other forums is permitted, provided the original author(s) or licensor are credited and that the original publication in this journal is cited, in accordance with accepted academic practice. No use, distribution or reproduction is permitted which does not comply with these terms. 